\title{
Properties of a Basic Amino Acid Permease in Neurospora crassa
}

\author{
By W. B. ROESS* AND A. G. DEBUSK \\ Genetics Laboratories, Department of Biological Sciences, \\ Florida State University, Tallahassee, Florida 32306
}

(Accepted for publication I6 February 1968)

\begin{abstract}
SUMMARY
The system for transporting arginine into Neurospora conidia is described and shown to be consistent with the permease concept. The arginine system is shown to be separate from that which transports the aromatic and branched-chain neutral amino acids. Metabolic energy is necessary to achieve a concentration of arginine in the conidia higher than the external medium but not to maintain this concentration differential. A canavanine resistant mutant is shown to transport the basic amino acids at a reduced rate but the mutant transports other amino acids at the normal rate.
\end{abstract}

\section{INTRODUCTION}

Rickenberg, Cohen, Buttin \& Monod (1956) described a special type of active transport involving the accumulation of sugars by Escherichia coli. They proposed that special molecules, probably protein in nature, bring about the catalytic transport of substances across the cell membrane. They termed these components permeases. The permease concept implied only two essential hypotheses: (I) there is a transient specific complex between the substance to be transported and the permease. (2) The permease is functionally specialized and not involved in intra-cellular metabolism.

The permease concept and the chemical nature of the permease molecule have recently been substantially clarified. Fox \& Kennedy (1965), identified a protein component in the cell membrane fraction of Escherichia coli as the gene product which functions in the transport of $\beta$-galactosides. Kolber \& Stein (1966) also identified a protein component in a cell fraction as the product of the $\beta$-galactoside permease gene of $E$. coli. Kaback \& Stadtman (1966) showed that isolated membranes from $E$. coli could catalyze the transport and concentration of proline. However, membranes from a transport deficient strain did not catalyze the uptake and concentration of proline.

DeBusk \& DeBusk (1965) have described a permease system for the transport of phenylalanine in Neurospora crassa. They showed that the basic amino acids are poor inhibitors of phenylalanine transport. Stadler (I966) has reported studies on the transport deficiencies of a number of 4-methyltryptophane resistant mutants of Neurospora. These mutants show a large reduction in the transport of the aromatic amino acids and several neutral alaphatic amino acids but minor reduction in the transport of the basic amino acids. Evidence for separate permeases functioning in the transport of arginine and lysine into yeast cells have been reported (Grenson, Mousset, Wiame \& Bechet, I966; Grenson, 1966).

* Present address: Science Division Florida Presbyterian College, St Petersburg, Florida. 
The purposes of this report are: (I) to describe the arginine transport system in Neurospora crassa; (2) to show that there are at least two separate permease systems in Neurospora for the transport of amino acids; (3) to show that arginine and lysine are probably transported by a common permease system; (4) to demonstrate that the energy requiring step for arginine transport operates during the influx process not by altering efflux properties; (5) to show that metabolic energy is required to achieve a concentration of arginine inside the cell greater than the external medium, but not to maintain this concentration differential; (6) to describe some properties of a transport deficient mutant.

\section{METHODS}

\section{Strains employed and maintenance of cultures}

Neurospora crassa wild-type strains 74A (OR) and sY 4f8a were used. Strain 74A was used as the standard in all experiments except those involving canavanine resistance, in which case SY $4 \mathrm{f} 8 \mathrm{a}$ was the standard wild type. The mutant strain CR-Io was isolated by one of the present authors (W.B.R.). It is an ultraviolet-light-induced mutant derived from wild type sy $4 \mathrm{f} 8 \mathrm{a}$. It was initially characterized as a canavanine resistant mutant. Canavanine is an analogue of arginine which will inhibit the growth of strain SY 4 f 8 a.

All cultures were grown and maintained on $25 \mathrm{ml}$. of Vogel minimal medium $\mathrm{N}$ (Vogel, 1956) containing $2 \%$ sucrose and $2 \%$ Difco agar. The cultures were either allowed to grow for 5-7 days at $30^{\circ}$ or transferred after $24 \mathrm{hr}$ to $25^{\circ}$ and allowed to grow for a total of 5-7 days before harvesting. The second procedure was found to improve conidiation. For transport experiments, conidia were harvested, suspended in cold sterile water, and filtered to remove mycelial pieces. Samples were removed and dried to determine the dry weight.

\section{Measurement of amino acid transport}

The basic incubation mixture for transport experiments included: (I) Vogel minimal medium N (Vogel, I956); (2) a ${ }^{14} \mathrm{C}$ uniformly labelled L-amino acid, usually $0.02-$ $0.04 \mu \mathrm{c} / \mathrm{ml}$. (obtained from Schwarz Bio Research); (3) non-radioactive L-amino acid to adjust the concentration of the amino acid to the desired specific activity, which was usually either 0.5 or 0.25 . The experiments were initiated by adding the conidial suspension to the incubation mixture which was previously adjusted to $30^{\circ}$. The conidia were kept in suspension by shaking in a constant temperature water bath.

Samples $(5 \mathrm{ml}$.) were removed from the incubation mixture at programmed times and deposited on a membrane filter (millipore HA $0.45 \mu, 25 \mathrm{~mm}$ ). The samples were washed with 5 volumes of water and glued to a planchet for later counting in a Baird Atomic thin window gas flow proportional counter. The results in the text, unless otherwise indicated, express the total amount of radioactive amino acid taken up by the conidia.

\section{Measurement of intra-cellular pools}

When measuring the free amino acid pool two $5 \mathrm{ml}$. samples were removed from the basic mixture. The first sample was immediately filtered and washed as previously described. The second sample was added to $10 \mathrm{ml}$. of $10 \%$ cold trichloroacetic acid (TCA) and after $30 \mathrm{~min}$. the cells were filtered and washed in the usual fashion. From differences in the radioactivity between these samples the size of the free pool was determined. 


\section{Measurement of concentration gradient}

The conidial volume of a $5 \mathrm{ml}$. sample (taken from the usual incubation medium for a transport experiment) was determined from the packed cell volume of the original concentrated suspension of conidia. The ratio of the free intracellular arginine to that remaining in the incubation mixture after the conidia had been removed gave an approximation of the gradient established at a particular time.

The magnitude of the concentration gradient was also determined in another way. Hot water extracts of conidia were analysed on a Beckman amino acid analyser. The conidia (5-6 mg.) were suspended in $5 \mathrm{ml} . \mathrm{H}_{2} \mathrm{O}$ after a $3 \mathrm{hr}$ incubation in the basic incubation mixture containing L-arginine- ${ }^{12} \mathrm{C}$. The control conidia were incubated without arginine. The conidia were boiled for $25 \mathrm{~min}$. and then centrifuged. The supernatant was decanted, chilled, recentrifuged and adjusted to $\mathrm{pH} 2 \cdot \mathrm{I}$ with $\mathrm{O} \cdot \mathrm{I} \mathrm{N}-\mathrm{HCl}$ to a final volume of $5 \mathrm{ml}$. Part of this sample was then passed through the amino acid analyser. The difference in arginine concentration between the experimental value and that obtained with control conidia was used to determine the concentration of free arginine which was accumulated in a unit volume of packed conidia.

\section{Chromatograpny of hot water extracts}

Following an incubation in $\mathrm{L}$-arginine- ${ }^{14} \mathrm{C}$, amino acids were extracted from conidia with hot water. These extracts were chromatographed employing one dimensional paper chromotography with water-saturated phenol used as a solvent. The chromatogram strips were developed with ninhydrin and the radioactivity was determined by counting the strips in a windowless Nuclear-Chicago Actigraph.

\section{RESULTS}

Transport of arginine into conidia of Neurospora crassa is temperature dependent. The temperature optimum for the arginine transport system occurs between $30^{\circ}$ and $40^{\circ}$ (Fig. I). The rates of transport at $40^{\circ}$ and $50^{\circ}$ were not constant but declined as the incubation proceeded, indicating an inactivation of the transport system at these temperatures. At zero degrees there was no accumulation of arginine in the cells above the concentration in the medium.

The transport of arginine in Neurospora is also $\mathrm{pH}$ dependent. The optimal $\mathrm{pH}$ is about 5.6 (Fig. 2). The results illustrated in Fig. 2 were obtained from experiments in which potassium phosphate solutions $(0 . \mathrm{I} M)$ were used as the incubation media. Using other buffers (citrate, tris, sodium phosphate) over small $\mathrm{pH}$ ranges it was confirmed that the optimal $\mathrm{pH}$ for arginine transport is between 5 and 6. Since Vogel minimal medium is buffered in this range it was used in all subsequent experiments as the incubation medium.

\section{Effect of the external arginine concentration}

At relatively low arginine concentrations the rate of transport was shown to depend on the concentration in the medium. However, the rate was not increased by raising the arginine concentration above $0.6 \mu$ moles $/ 30 \mathrm{ml}$. (Fig. 3). In this experiment each $\mathrm{ml}$. of incubation medium contained $\mathrm{o} \cdot \mathrm{I} \mathrm{mg}$. (dry wt) of conidia.

Initial velocities of arginine transport were obtained in an experiment similar to that 
illustrated in Fig. 3, but in this second experiment lower concentrations were used. The data obtained from samples incubated for 5 and $10 \mathrm{~min}$. were considered to represent initial velocities, since there was no change in the transport rate during this time. The data were plotted according to the methods of Lineweaver \& Burk (I934) (Fig. 4). From these experiments a typical $\mathrm{Km}$ of $2 \times 10^{-6} \mathrm{M}$ was obtained. This value corresponds to a concentration of $0.002 \mu \mathrm{moles} / \mathrm{ml}$. Independent determinations of a $\mathrm{Km}$ value have varied between $1 \cdot 74 \times 10^{-6} \mathrm{M}$ and $2 \cdot 1 \times 10^{-6} \mathrm{M}$. In each case points for the highest concentrations do not lie on the line as drawn in Fig. 4. We have no explanation for this but it is typical of plots showing high substrate inhibition.

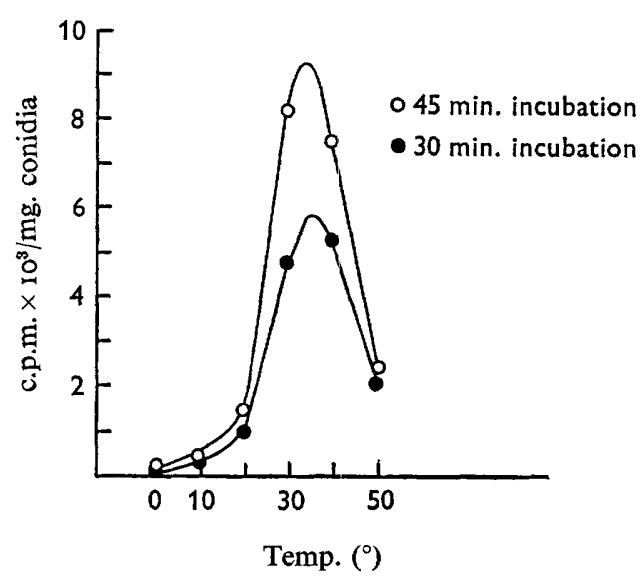

Fig. I

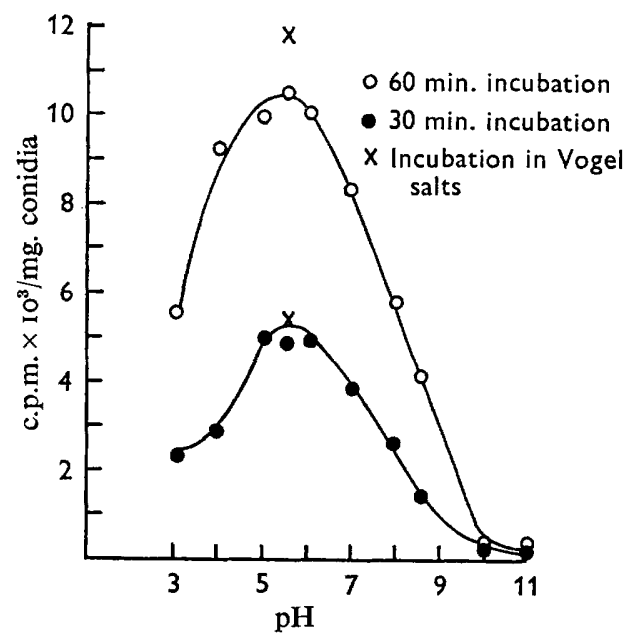

Fig. 2

Fig. I. Arginine transport as a function of temperature. The basic incubation mixture contained ${ }^{0.1} 14 \mathrm{mM}$-L-arginine- ${ }^{14} \mathrm{C}$ with a specific activity of $0.35 \mu \mathrm{C} / \mu$ mole. The conidial concentration was $0.06 \mathrm{mg}$. (dry wt) $/ \mathrm{ml}$.

Fig. 2. Arginine transport as a function of $\mathrm{pH}$. Potassium phosphate (O.I M) solutions were used as the incubation mixtures containing $0.08 \mathrm{mM}$-L-arginine- ${ }^{14} \mathrm{C}$ with a specific activity of $0.5 \mu \mathrm{c} / \mu$ mole. The conidial concentration was $0.08 \mathrm{mg}$. (dry wt) $/ \mathrm{ml}$. in a total initial volume of $25 \mathrm{ml}$. The incubations in Vogel salts were for 30 and $60 \mathrm{~min}$.

\section{Measurement of transport gradient}

Arginine can be transported against a concentration gradient. Under the conditions of limited incorporation of amino acids into protein (incubation without glucose or with actidione added to inhibit protein synthesis) the arginine pool was near its maximum size after $3 \mathrm{hr}$ of incubation. The ratio of arginine in the pool of a unit volume of packed conidia to the concentration remaining in an equal volume of the incubation medium was calculated to be 3I4. Hot water extracts of the conidia were chromatographed to establish the percentage of radioactivity which was still associated with arginine. These results showed that less than $5 \%$ of the arginine was converted to other forms. There was a small amount of radioactivity in the ornithine spot on the chromatogram and in another spot which was not identified but was probably urea. The arginine concentration value in the hot water extracts was also obtained by passing a sample (non-radioactive) through an amino acid analyser. In this case the concentra- 
tion of arginine in conidia incubated in medium containing arginine was shown to be I $5 \mu \mathrm{moles} / \mathrm{ml}$. of packed conidia above the control level. The ratio of arginine concentration in the cells to that in the medium was 444 . The amount of radioactivity which was not extractable with hot water or cold trichloroactic acid (TCA) was used to indicate what percentage of the total arginine taken up was incorporated into protein. Under standard conditions (no glucose added) the amount incorporated into TCA insoluble material was less than $15 \%$.

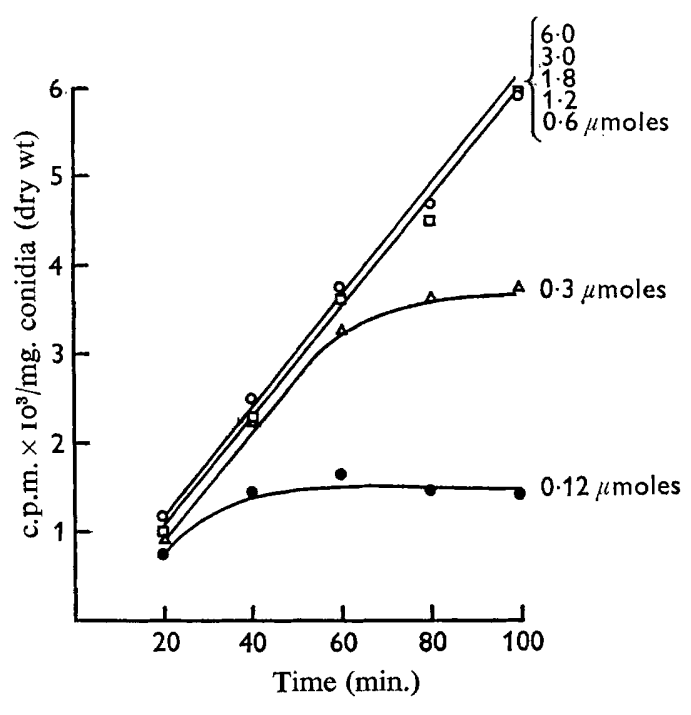

Fig. 3

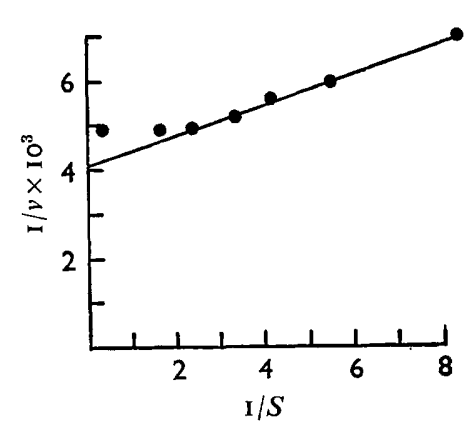

Fig. 4

Fig. 3. Arginine transport as a function of external arginine concentration. The basic incubation mixture $(30 \mathrm{ml}$.) contained L-arginine with a specific activity of 0.17 . The concentrations indicated are expressed as $\mu$ moles $/ 30 \mathrm{ml}$. The conidial concentration in each case was $0 \cdot 1 \mathrm{mg}$ (dry wt)/ml.

Fig. 4. Lineweaver-Burk plot of $L$-arginine transport. The initial velocities are expressed as $\mu$ moles of $\mathrm{L}$-arginine transported per $\mathrm{mg}$. dry $\mathrm{wt} / \mathrm{minute}$. The substrate concentrations are expressed as $\mu$ moles per $40 \mathrm{ml}$.

\section{The energy requirement in the transport process}

The transport of arginine was inhibited by 2,4-dinitrophenol (0.42 mM). This compound immediately inhibited arginine transport if added after $40 \mathrm{~min}$. or added at the beginning of the incubation (Fig. 5). It can also be seen (Fig. 5) that there is little or no efflux of the arginine from the cells after the energy generating system is inhibited. Nearly identical results were obtained when sodium azide was used as the inhibitor. Since the mechanism of inhibition of oxidative phosphorylation by 2, 4-DNP and $\mathrm{NaN}_{3}$ is not clearly understood, another inhibitor was used to determine what effect the loss of ATP formation has on arginine transport. Antimycin A inhibits the reoxidation of coenzyme Q of the electron transport system (Green, Hatefi \& Fechner, 1959). This antifungal agent caused a similar inhibition of arginine transport (Fig. 6). Attention is again directed to the lack of efflux of previously accumulated arginine when an ATP generating system was inhibited. Under nearly identical conditions DeBusk \& DeBusk 


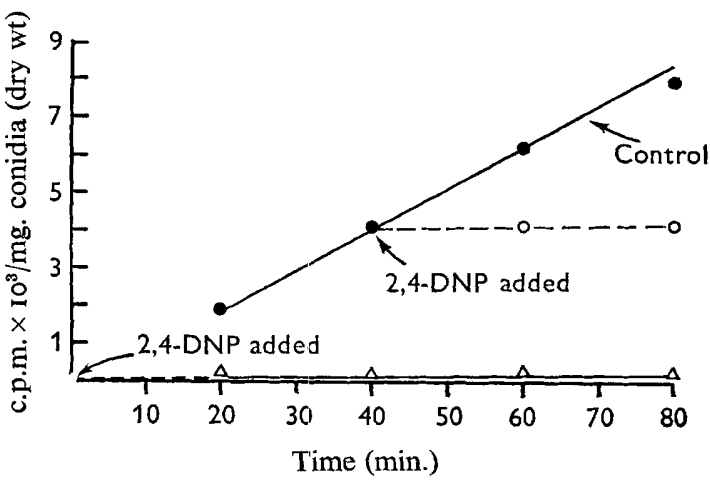

Fig. 5

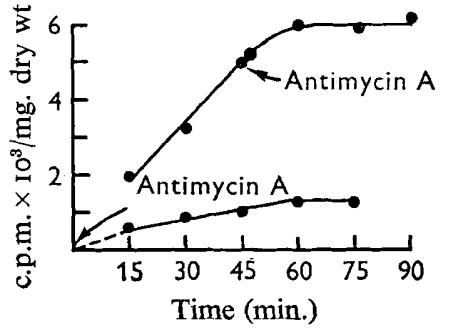

Fig. 6

Fig. 5. The effect of 2,4-dinitrophenol (2,4-DNP) on arginine transport. The basic incubation mixture $(30 \mathrm{ml})$. contained $0.03 \mathrm{mM}$-L-arginine- ${ }^{14} \mathrm{C}$ with a specific activity of $0.25 \mu \mathrm{C} / \mu \mathrm{mole}$. The conidial concentration was $0.06 \mathrm{mg}$. (dry wt)/ml. The concentration of $2,4-\mathrm{DNP}$ was $0.42 \mathrm{~mm}$.

Fig. 6. The effect of antimycin A (0.01 $\mathrm{mg} . / \mathrm{ml})$. on arginine transport. The basic incubation mixture $(50 \mathrm{ml}$.) contained $0.04 \mathrm{~mm}-\mathrm{L}$-arginine with a specific activity of $0.5 \mu \mathrm{c} / \mu \mathrm{mole}$. The conidial concentration was $0.04 \mathrm{mg}$. (dry wt) $/ \mathrm{ml}$.

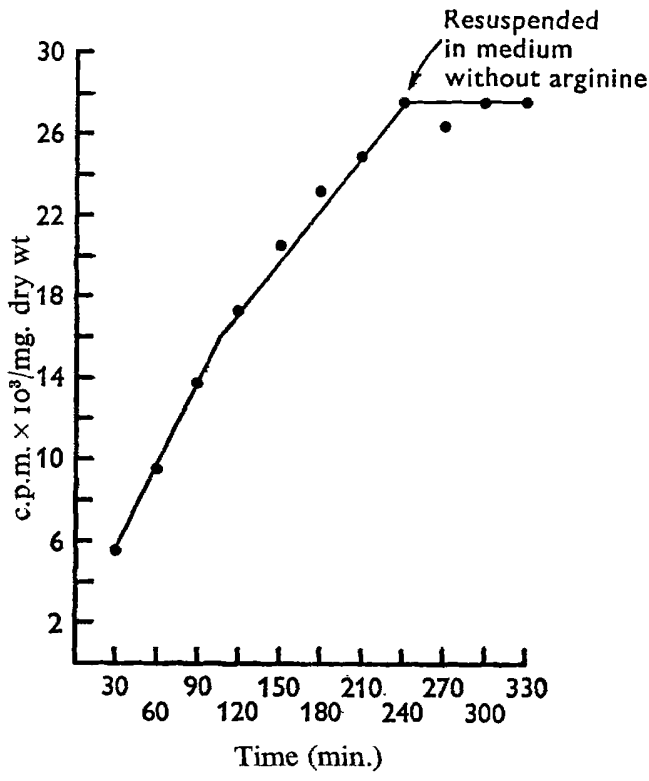

Fig. 7

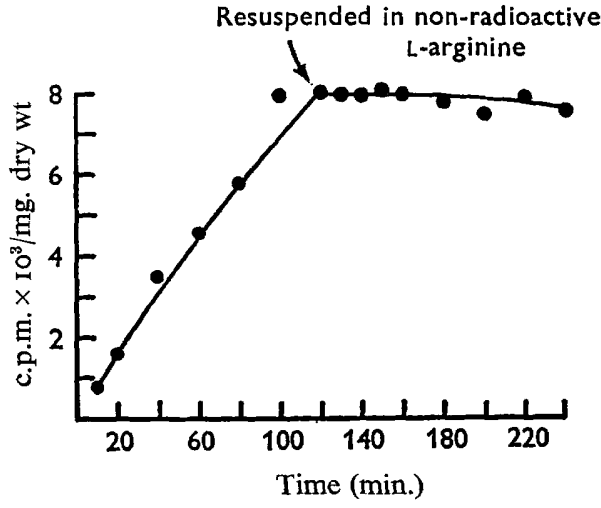

Fig. 8

Fig. 7. Lack of efflux of arginine after resuspending in medium without arginine. The basic incubation mixture ( $100 \mathrm{ml}$.) contained $0.08 \mathrm{mM}-\mathrm{L}$-arginine $-{ }^{14} \mathrm{C}$ with a specific activity of $0.5 \mu \mathrm{c} / \mu \mathrm{mole}$. The conidial concentration was $0.06 \mathrm{mg}$. (dry wt) $/ \mathrm{ml}$. The actidione concentration was $0.2 \mathrm{mg} . / \mathrm{ml}$.

Fig. 8. Lack of exchange of pool arginine with arginine in the external medium. The basic incubation medium ( $100 \mathrm{ml}$.) contained $0.16 \mathrm{~mm}$-L-arginine $-{ }^{14} \mathrm{C}$ with a specific activity of $0.25 \mu \mathrm{c} / \mu$ mole. The conidial concentration was $0.05 \mathrm{mg}$. (dry wt) $/ \mathrm{ml}$. The cells were resuspended in $0.16 \mathrm{~mm}$-L-arginine-12 $\mathrm{C}$. 
(I965) found that phenylalanine was not maintained in the cells when $\mathrm{NaN}_{3}$ and 2-4DNP were added.

The lack of efflux of accumulated arginine was further examined. Conidia incubated for $4 \mathrm{hr}$ in the basic medium containing radioactive arginine were resuspended in medium without arginine. No efflux was observed (Fig. 7). This experiment was carried out with actidione added to stop protein synthesis. Similar results were obtained when cells were incubated for only $3 \mathrm{hr}$ before resuspending them.

Efflux could not be demonstrated in the absence of an external source of arginine even though a large arginine pool was maintained by the cells. The question remained whether the arginine in this pool would exchange with the arginine in the external medium. To answer this question, conidia were incubated in radioactive arginine for $2 \mathrm{hr}$. They were removed from the medium containing radioactive arginine, washed with distilled water and resuspended in medium with unlabelled arginine. As seen in Fig. 8, no efflux or exchange of the arginine in the cells with that in the external medium was obtained.

\section{Determination of stereospecificity and inhibition by L-amino acids}

The transport of L-arginine was not affected by the addition of D-arginine. Table I shows that the addition of non-radioactive L-arginine reduced the transport of the labelled $\mathrm{L}$ isomer, whereas the $\mathrm{D}$-isomer did not.

Table I. Effect of $D$ - and L-isomers of arginine on L-arginine transport

$\begin{array}{ccccc}\begin{array}{c}\text { Additions* } \\ \text { Time of }\end{array} & \text { Control } & \begin{array}{c}\text { I } \mu \text { mole } \\ \text { L-arginine-12C }\end{array} & \begin{array}{c}\text { I } \mu \text { mole } \\ \text { D-arginine-12 }\end{array} & \begin{array}{c}5 \mu \text { moles } \\ \text { D-arginine-12C }\end{array} \\ \begin{array}{c}\text { incubation } \\ \text { in minutes }\end{array} & \text { L-Arginine uptake expressed as counts per minute/mg. dry wt } \\ \text { I5 } & 2,800 & 1,518 & 3,180 & 2,798 \\ 30 & 7,200 & 4,000 & 7,600 & 6,930 \\ 45 & 11,600 & 6,000 & 11,500 & 10,700 \\ 60 & 15,700 & 8,100 & 15,100 & 14,400\end{array}$

* Each incubation flask contained $0.04 \mathrm{mM}-\mathrm{L}$-arginine- ${ }^{14} \mathrm{C}$ with a specific activity of $\mathrm{I} \mu \mathrm{c} / \mu \mathrm{mole}$ in $25 \mathrm{ml}$. of the basic medium.

Many of the naturally occurring amino acids inhibit the transport of arginine. Table 2 shows the results of amino acid inhibition experiments. The inhibiting amino acids were present at concentrations of 20,50 and $100 \mu$ moles per $25 \mathrm{ml}$. in combination with one $\mu$ mole of $\mathrm{L}$-arginine. These results show that the basic amino acids lysine and ornithine were the best inhibitors; glutamic acid, a dicarboxylic amino acid, was a poor inhibitor; and the neutral amino acids were intermediate. Proline, an imino acid, was not inhibitory to arginine transport.

In order to determine if the uptake inhibition by non-basic amino acids was occurring at the entry site or through a competition for a common pool, the following experiment was done. Conidia were incubated for varying times in the basic medium containing phenylalanine. The cells were removed from the phenylalanine medium, washed and suspended in medium with labelled arginine. The rate of arginine transport was examined and compared in these cells containing varying phenylalanine pool concentrations. The phenylalanine pool concentrations were previously measured and shown to increase linearly over the first $60 \mathrm{~min}$. of incubation (DeBusk \& DeBusk, 
I965). Table 3 shows that phenylalanine previously accumulated by the cells did not affect the transport of arginine. This result indicated that the inhibition of arginine by phenylalanine appeared to be at the transport level rather than at the pool level. The term 'pool' is defined as, that concentration of amino acid which can be extracted from the cell under conditions which cause no degradation of macromolecules.

Table 2. Effects of other amino acids on the transport of L-arginine in wild type strain 74A. Arginine uptake expressed as percentage of control

$\begin{array}{lcccr}\text { Inhibiting amino acid } & \text { IO:I* } & 20: 1 & 50: I & \text { IOO: } 1 \\ \text { Lysine } & 28 \cdot 8 & \mathrm{I} 5 \cdot 2 & - & 5 \cdot 2 \\ \text { Ornithine } & - & 29 \cdot 6 & 18 \cdot 3 & 12 \cdot 0 \\ \text { Histidine } & - & 40 \cdot 0 & 27 \cdot 5 & 28 \cdot 0 \\ \text { Phenylalanine } & 43 \cdot 5 & 42 \cdot 6 & - & 33 \cdot 6 \\ \text { Tryptophan } & - & 32 \cdot 0 & 32 \cdot 0 & 27 \cdot 5 \\ \text { Citrulline } & - & 55 \cdot 4 & 4 \mathrm{I} \cdot 6 & 36 \cdot 0 \\ \text { Alanine } & 55 \cdot 8 & 49 \cdot 0 & - & 41 \cdot 0 \\ \text { Isoleucine } & - & 54 \cdot 0 & 44 \cdot 5 & 37 \cdot 2 \\ \text { Leucine } & - & 46 \cdot 8 & 41 \cdot 0 & 42 \cdot 2 \\ \text { Methionine } & - & 44 \cdot 5 & 40 \cdot 0 & 39 \cdot 2 \\ \text { Serine } & - & 68 \cdot 0 & 55 \cdot 0 & 47 \cdot 0 \\ \text { Glutamic acid } & - & 96 \cdot 0 & 78 \cdot 0 & 54 \cdot 0 \\ \text { Glycine } & - & 75 \cdot 5 & 60 \cdot 3 & 53 \cdot 0 \\ \text { Threonine } & - & 73 \cdot 0 & 65 \cdot 0 & 50 \cdot 0 \\ \text { Proline } & - & 101 \cdot 0 & 98 \cdot 2 & 101 \cdot 0\end{array}$

* Ratio of inhibiting amino acid concentration to arginine concentration. The L-arginine- ${ }^{-14} \mathrm{C}$ conentration in each case was $0.04 \mathrm{~mm}$ with a specific activity of $0.5 \mu \mathrm{c} / \mu \mathrm{mole}$.

\section{Table 3. Effect of phenylalanine pool size on arginine transport}

\begin{tabular}{|c|c|c|c|c|c|}
\hline \multirow{3}{*}{$\begin{array}{l}\text { Time of } \\
\text { incubation } \\
\text { (min.)* }\end{array}$} & \multicolumn{5}{|c|}{$\begin{array}{l}\text { Minutes of previous incubation in the basic medium containing } \\
\qquad 0.08 \mathrm{mM}-\mathrm{DL}-\text { phenylalanine }\end{array}$} \\
\hline & 0 & 10 & 20 & 30 & 40 \\
\hline & \multicolumn{5}{|c|}{ L-Arginine uptake expressed as counts per minute/mg dry wt } \\
\hline 10 & 1,680 & $\mathrm{I}, 740$ & 1,960 & 1,925 & $\mathbf{I}, 970$ \\
\hline 20 & 3,360 & 3,225 & 3,560 & 3,410 & 3,360 \\
\hline 40 & 6,250 & 6,100 & 6,790 & 6,170 & 6,050 \\
\hline 60 & 8,790 & 8,650 & 8,650 & 9,000 & 8,430 \\
\hline 80 & 11,100 & 10,200 & I 1,780 & 10,750 & 10,810 \\
\hline
\end{tabular}

* Each incubation flask contained $0.08 \mathrm{mM}-\mathrm{M}-\mathrm{L}$-arginine- $\mathrm{C}^{14}$ with a specific activity of $0.5 \mu \mathrm{c} / \mu$ mole in $50 \mathrm{ml}$. of the basic medium.

\section{Simultaneous transport experiments in wild type $74 \mathrm{~A}$}

The specificity of the system transporting arginine needed further investigation. If separate systems existed for the transport of two different amino acids, it was reasoned that the accumulation of radioactivity by conidia incubated with two radioactive amino acids would be greater than the rate for either amino acid independently. However, the rate would be intermediate between the separate rates if the two amino acids were transported by a common system. The concentration of each amino acid in the medium had to be sufficiently high so that the separate rate of transport of the amino acid was independent of the external concentration. 
When lysine- ${ }^{14} \mathrm{C}$ and arginine $-{ }^{14} \mathrm{C}$ were simultaneously transported from the same incubation mixture, the resulting rate of ${ }^{14} \mathrm{C}$ accumulation was an average of the separate rates for arginine and lysine (Fig. 9). This indicates that arginine and lysine are transported by a common permease system. The results were quite different when the rates of transport of arginine $-{ }^{14} \mathrm{C}$ in combination with either tyrosine $-{ }^{14} \mathrm{C}$, leucine${ }^{14} \mathrm{C}$, or phenylalanine- ${ }^{14} \mathrm{C}$ were examined. In each of these cases the combined initial

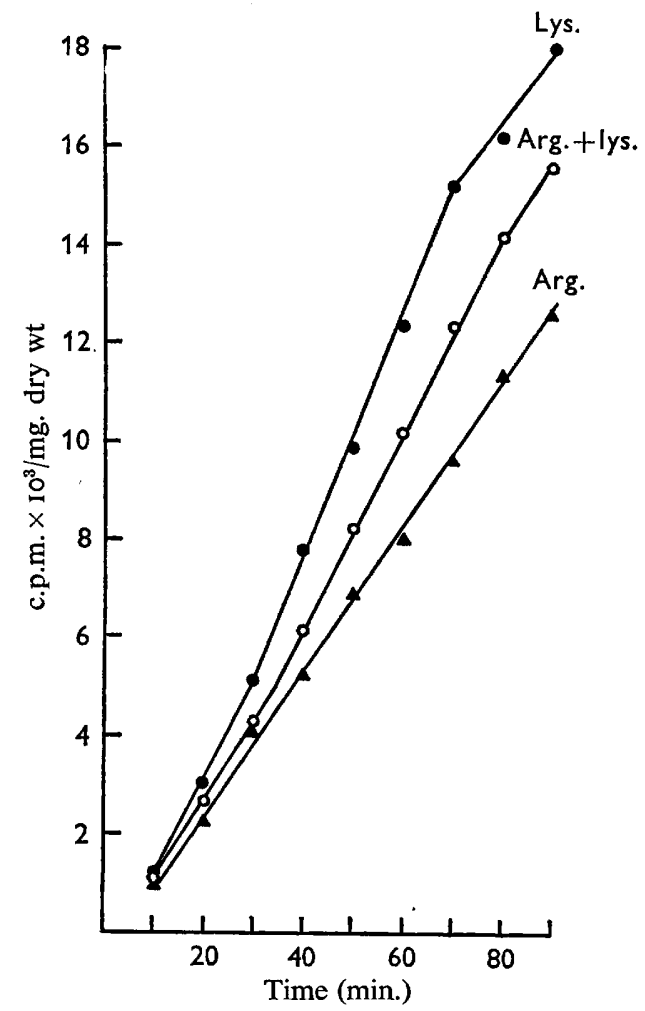

Fig. 9

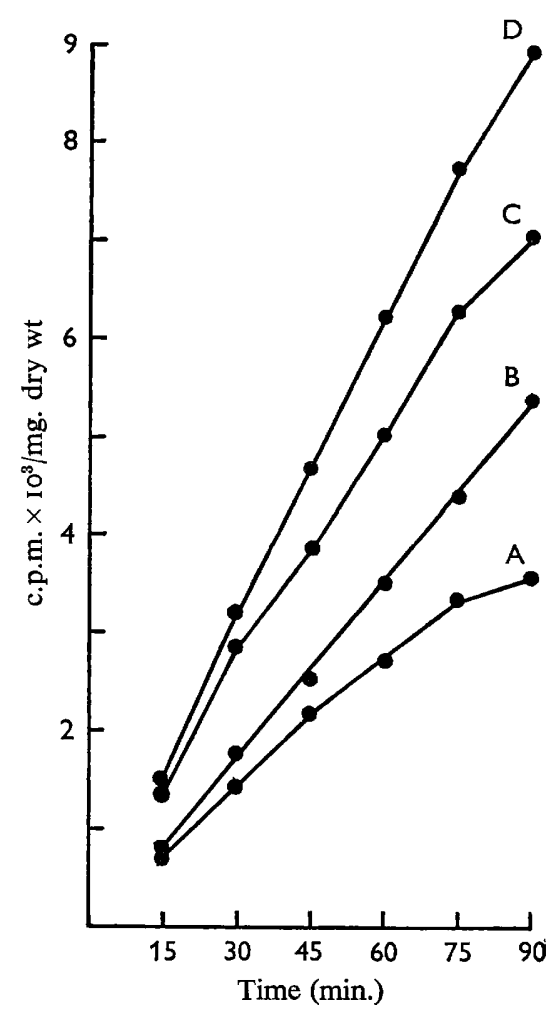

Fig. 10

Fig. 9. Comparison of the simultaneous and separate transport rates of L-arginine and L-lysine in a wild type strain $74 \mathrm{~A}$. The basic incubation mixture $(50 \mathrm{ml}$.) contained respectively:

(I) simultaneous transport; $0.08 \mathrm{mM}-\mathrm{L}$-arginine $-{ }^{14} \mathrm{C}$ with a specific activity of $0.5 \mu \mathrm{C} / \mu \mathrm{mole}$; $0.08 \mathrm{~mm}-\mathrm{L}-\mathrm{lysine}-{ }^{14} \mathrm{C}$ with a specific activity of $0.5 \mu \mathrm{C} / \mu \mathrm{mole}$.

(2) Arginine transport alone; $0.08 \mathrm{~mm}-\mathrm{L}$-arginine $-{ }^{14} \mathrm{C}$ with a specific activity of $0.5 \mu \mathrm{C} /$ umole.

(3) lysine transport alone; $0.08 \mathrm{mM}-\mathrm{L}-\mathrm{lysine}-{ }^{14} \mathrm{C}$ with a specific activity of $0.5 \mu \mathrm{C} / \mu$ mole.

(4) the concentration of conidia in each case was $0.07 \mathrm{mg}$. (dry wt)/ml.

Fig. Io. Comparison of simultaneous and separate transport rates of $\mathrm{L}$-arginine and $\mathrm{L}$-tyrosine. The basic incubation mixtures $(50 \mathrm{ml}$.) contained respectively:

Curve A. L-tyrosine- ${ }^{14} \mathrm{C}(0.08 \mathrm{~mm})$ with a specific activity of $0.25 \mu \mathrm{c} / \mu \mathrm{mole}$.

Curve B. L-arginine- ${ }^{14} \mathrm{C}(0.08 \mathrm{~mm})$ with a specific activity of $0.25 \mu \mathrm{C} / \mu \mathrm{mole}$.

Curve C. L-tyrosine- ${ }^{14} \mathrm{C}(0.8 \mathrm{~mm})$ with a specific activity of $0.25 \mu \mathrm{C} / \mu$ mole plus $\mathrm{L}$-arginine${ }^{14} \mathrm{C}(0.08 \mathrm{~mm})$ with a specific activity of $0.25 \mu \mathrm{c} / \mu$ mole.

Curve D is the calculated sum of Curve A+Curve B. The conidial concentration in each case was $0.07 \mathrm{mg}$. (dry wt) $/ \mathrm{ml}$. 
rate was clearly greater than either of the two separate rates and closely approached a calculated sum of the separate rates. A typical result is illustrated in Fig. IO.

The transport of phenylalanine- ${ }^{14} \mathrm{C}$ in combination with leucine- ${ }^{14} \mathrm{C}$ or tyrosine $-{ }^{14} \mathrm{C}$ resulted in each case in a ${ }^{14} \mathrm{C}$ accumulation rate intermediate between the separate rates. This result suggests that phenylalanine, tyrosine and leucine are transported by a common permease. These results are consistent with the inhibition results for phenylalanine transport reported by DeBusk \& DeBusk (1965) and the growth inhibition experiments of Brockman, DeBusk \& Wagner (I959).

\section{Properties of a canavanine resistant mutant}

If, as indicated by the above results, a specific permease functions in the transport of the basic amino acids, a mutant should be obtainable which has reduced transport capacity for only the basic amino acids. In order to find such a mutant we isolated strains which would grow on canavinine (an analogue of arginine). One of the mutants designated CR-Io fits this description (Table 4). Arginine, lysine and histidine were transported at reduced rates whereas other selected amino acids and a glucose analogue, 3,0-methylglucose were transported at the normal rate.

Table 4. Comparison of transport between wild type strain SY 4 fga and mutant strain CR IO*

\begin{tabular}{|c|c|c|c|c|c|c|c|c|c|c|}
\hline \multirow{2}{*}{$\begin{array}{l}\text { Time } \\
\text { (min.) }\end{array}$} & \multicolumn{2}{|c|}{ Arginine } & \multicolumn{2}{|c|}{ Lysine } & \multicolumn{2}{|c|}{ Histidine } & \multicolumn{2}{|c|}{ Phenylalanine } & \multicolumn{2}{|c|}{ Leucine } \\
\hline & Wt & CR IO & Wt & CR IO & Wt & CR IO & Wt & CR IO & Wt & CR IO \\
\hline 15 & 970 & 565 & $242 \mathrm{I}$ & 1504 & 1389 & 901 & 1759 & 2143 & 1487 & 1804 \\
\hline 30 & 1710 & 1017 & 4395 & 2713 & 2303 & 1659 & 2662 & $326 \mathrm{I}$ & 2680 & 3270 \\
\hline 45 & 2453 & 1500 & 6083 & 4213 & 3180 & 2360 & 3197 & 3840 & 3640 & 4048 \\
\hline 60 & 3200 & 2022 & 8004 & 5152 & 3930 & 2810 & 3618 & 4130 & 3947 & 4970 \\
\hline \multirow[t]{3}{*}{75} & 3910 & 2467 & 9754 & 6235 & 4643 & 3462 & 3360 & 3973 & 4364 & 4930 \\
\hline & \multicolumn{2}{|c|}{ Alanine } & \multicolumn{2}{|c|}{ Serine } & \multicolumn{2}{|c|}{ Glycine } & \multicolumn{2}{|c|}{ Aspartic acid } & \multicolumn{2}{|c|}{ 3-methyl glucose } \\
\hline & Wt & CR IO & Wt & CR IO & Wt & CR 10 & Wt & CR IO & Wt & CR 10 \\
\hline 15 & 1266 & 1630 & 1209 & I 397 & 1727 & I 835 & 149 & I5I & 496 & 430 \\
\hline 30 & 2330 & 2810 & 2277 & 2526 & 3125 & 3626 & 273 & 250 & 623 & 570 \\
\hline 45 & 3314 & 3594 & $334 \mathrm{I}$ & 3793 & 4448 & 4905 & 360 & 328 & 1053 & 904 \\
\hline 60 & 4189 & 4909 & 4215 & 4504 & 5820 & 6672 & 466 & 474 & 1456 & 1307 \\
\hline 75 & 5138 & 6194 & 5406 & 5582 & 7262 & 8332 & 615 & 608 & 1890 & I 680 \\
\hline
\end{tabular}

* All experiments conducted with $5 \mathrm{mg}$. $/ \mathrm{ml}$. of actidione added. The specific activity of each amino acid was the same (I $\mu \mathrm{c} / 4 \mu$ moles) except lysine ( $2 \mu \mathrm{c} / 4 \mu$ moles). O-methyl-glucose specific activity was I $\mu \mathrm{C} / \mathrm{I}$ o $\mu$ moles. All results are expressed as counts/minute/mg. dry wt conidia.

\section{DISCUSSION}

Evidence had been presented here to support the conclusion that arginine is actively transported across the cell membrane of Neurospora crassa conidia by a constitutive stereospecific system. Establishment of a 400-fold difference in the concentration inside the conidia over the external medium was demonstrated. The transport process which established this gradient was shown to require metabolic energy and is dependent on the $\mathrm{pH}$ of the medium and the temperature. This transport system also showed saturation kinetics typical of enzymic reactions. 
Koch (I964) and Winkler \& Wilson (1966), studying galactoside transport in Escherichia coli, proposed that the energy step in active transport brings about a decrease in the efflux rate of the galactoside resulting in a net increase in influx. In Neurospora previously accumulated arginine does not efflux in the absence of external arginine or exchange with arginine in the medium, and no efflux is observed when energy poisons are employed. Therefore a different explanation involving energy utilization must be proposed for arginine accumulation in Neurospora.

The experiments described here suggest that the energy step in arginine transport is directly involved in influx, not in reducing an efflux system. This implies that energy is expended to achieve a high concentration gradient of arginine inside the cell but not to maintain it.

The results of the experiments involving the simultaneous transport of two labelled amino acids argue for the existence of at least two separate permeases. Each of these permeases is thought to be shared by separate groups of amino acids. One group composed of the basic amino acids and the other the branched and aromatic neutral amino acids.

The simultaneous rates were not in any case completely equal to the sum of the separate rates. This observation along with the observed interference by the non-basic amino acids on arginine transport would indicate that some overlap in function of the separate permeases exists or there is an additional less specific transport system. Another likely explanation is that the cross inhibitions which are observed occur at a secondary step subsequent to the interaction of the permeases with the amino acids.

This research was supported in part by a Public Health Service Fellowship (W.B. R.) GM-I 5,934 and by a Research Training Grant (T or GMor3r6) from the National Institutes of General Medical Sciences.

\section{REFERENCES}

Brockman, H. E., DeBusk, A. G. \& Wagner, R. P. (1959). Mutant-associated antagonisms in Neurospora crassa. Arch. Biochem. Biophys. 84, 455.

DeBusk, B. G. \& DeBusK, A. G. (1965). Molecular transport in Neurospora crassa. I. Biochemical properties of a phenylalanine permease. Biochim. biophys. Acta 104, 139.

Fox, C. F., \& KenNedy, E. P. (1965). Specific labeling and partial purification of the M protein, a component of the $\beta$-galactoside transport system of Escherichia coli. Proc. natn. Acad. Sci. U.S. $54,89 \mathrm{I}$.

Green, D. E., Hatefi, Y. \& Fechner, W. F. (1959). On the role of coenzyme Q in electron transport. Biochem. biophys. Res. Commun. I, 45.

Grenson, M., Mousset, M., Wiame, J. M. \& Bechet, J. (1966). Multiplicity of the amino acid permeases in Saccharomyces cerevisiae I. Evidence for a specific arginine-transporting system. Biochim. biophys. Acta 127, 325.

Grenson, M. (1966). Multiplicity of the amino acid permease in Saccharomyces cerevisiae II. Evidence for a specific lysine-transporting system. Biochim. biophys. Acta 127, 339.

Kaback, H. R. \& Stadtman, E. R. (I966). Proline uptake by an isolated cytoplasmic membrane preparation of Escherichia coli. Proc. natn. Acad. Sci. U.S. 55, 920.

Koch, A. L. (1964). The role of permease in transport. Biochim. biophys. Acta. $79,177$.

Kolber, A. R. \& STein, W. D. (1966). Identification of a component of a transport carrier system: isolation of the permease expression of the Lac Operon of Escherichia coli. Nature, Lond. 209, 69I.

Lineweaver, H. \& BURK, D. (1934). The determination of enzyme dissociation constants. J. Am. chem. Soc. $\mathbf{5 6}^{6}, 658$ 
Rickenberg, H. V., Cohen, G. N., Butrin, G. \& Monod, J. (I956). La galactoside-permease d'Escherichia coli. Annls Inst. Pasteur, Paris 9, 829.

Stadler, D. R. (1966). Genetic control of the uptake of amino acids in Neurospora. Genetics, Princeton 54, 677 .

VoGel, H. J. (1956). A convenient growth medium for Neurospora. Microb. Genet. Bull. 13, 42.

WINKLER, H. H. \& WILSON, T. H. (1966). The role of energy coupling in the transport of $\beta$-galactosides by Escherichia coli. J. biol. Chem. 24r, 2200. 